\title{
O ÉPICO, O PERSPECTIVISMO, A MISCIGENAÇÃO E A MALANDRAGEM NAS FRICÇÕES ENTRE O ARTISTA-PESQUISADOR E O PESQUISADOR-ARTISTA
}

THE EPIC, THE PERSPECTIVISM, THE MISCEGENATION AND THE MALICE IN FRICTIONS BETWEEN THE ARTIST-RESEARCHER AND THE RESEARCHER-ARTIST

LO ÉPICO, LO PERSPECTIVISMO, EL MESTIZAJE $Y$ LA PICARDÍA EN LOS ENFRENTAMIENTOS ENTRE EL ARTISTA-INVESTIGADOR Y EL INVESTIGADOR-ARTISTA

\section{Luiz Eduardo Frin}

Luiz Eduardo Frin Doutorado pelo Instituto de Artes da Universidade Estadual Paulista (Unesp). Ator, cantor, diretor de teatro e dramaturgo.

Professor do curso profissionalizante do Indac (Instituto de Arte e Ciência) - Escola de Atores (São Paulo/SP) e da Escola de Artes Cênicas Wilson Geraldo (Santos/SP). 


\section{Resumo}

Neste trabalho, apresento resumidamente elementos da minha tese de doutorado Épica, em perspectiva, miscigenada e malandra: mergulhos em processos criativos da Cia. Livre e da Cia. Teatro Balagan trazem à tona forma de produção do sujeito teatro de grupo paulistano, em que defendi que a forma de produção desenvolvida pelo sujeito histórico teatro de grupo paulistano é predominantemente épica e comporta elementos fundantes do denominado povo brasileiro: a miscigenação, o perspectivismo e a malandragem. Além disso, relato neste artigo algumas fricções ocorridas no processo de pesquisa, concernentes às relações estabelecidas entre o sujeito pesquisador e o objeto de pesquisa, fricções estas que foram determinantes para a forma final ensaística do trabalho.

Palavras-chave: Épico, Perspectivismo, Miscigenação, Malandragem, Ensaio como forma.

\section{Abstract}

In this paper, I briefly present elements of my PhD dissertation Épica, em perspectiva, miscigenada e malandra: mergulhos em processos criativos da Cia. Livre e da Cia. Teatro Balagan trazem à tona forma de produção do sujeito teatro de grupo paulistano [Epic, in perspective, miscegenated and malicious: immersions in creative processes of the $\mathrm{Cia}$. Livre and of the Cia. Teatro Balagan bring to light production form of the subject São Paulo city theatre group], in which I argued that the form of production developed by the historical subject São Paulo city's theater group is predominantly epic and contains fundamental elements of the so-called Brazilian people: miscegenation, perspectivism and rascality. In addition, I report in this article some frictions that occurred in the research process, concerning the relations established between the researcher subject and the research object, frictions that were decisive for the final essay form of the work.

Keywords: Epic, Perspectivism, Miscegenation, Rascality, Essay as form. 


\section{Resumen}

En este trabajo presento resumidamente elementos de la tesis de doctorado Épica, em perspectiva, miscigenada e malandra: mergulhos em processos criativos da Cia. Livre e da Cia. Teatro Balagan trazem à tona forma de produção do sujeito teatro de grupo paulistano [Épica, en perspectiva, mezclada y pícara: inmersiones en procesos creativos de la Cia. Livre y de la Cia. Teatro Balagan sacan a la luz forma de producción del sujeto teatro de grupo de la ciudad de São Paulo], en que defendí que la forma de producción desarrollada por el sujeto histórico teatro de grupo de la ciudad de São Paulo es predominantemente épica y comporta elementos fundantes del llamado pueblo brasileño: el mestizaje, lo perspectivismo y la picardía. Además, relato en este artículo algunos enfrentamientos ocurridos durante el proceso de investigación, concernientes a las relaciones establecidas entre el sujeto investigador y el objeto de investigación, enfrentamientos que fueron determinantes para la forma final ensayística del trabajo.

Palabras clave: Épico, Perspectivismo, Mestizaje, Picardía, Ensayo como forma.

Em 2 de maio de 2017, defendi a tese: Épica, em perspectiva, miscigenada e malandra: mergulhos em processos criativos da Cia Livre e da Cia. Teatro Balagan trazem à tona forma de produção do sujeito teatro de grupo paulistano (FRIN, 2017). Neste artigo, além de compartilhar sinteticamente elementos da tese de doutoramento elaborada sob a orientação de Alexandre Mate no Instituto de Artes da Unesp, intento apresentar elementos que considero essenciais do processo de pesquisa do qual o trabalho foi resultante.

Como objeto de pesquisa, dentre a multifacetada produção teatral paulistana contemporânea, destaquei a realizada por grupos e companhias que trabalham a partir de ideais colaboracionistas de criação e de administração interna. Coletivos teatrais que compõem o sujeito histórico teatro de grupo paulistano. Artistas associados que, além de produzirem espetáculos teatrais, editam publicações, promovem debates, cursos e exercem atividade política militante. A partir da observação desse cenário, elaborei a seguinte hipótese: "a produção continuada de tantos coletivos teatrais paulistanos [...] estruturou 
arcabouço teatral práxico (que engloba prática e teoria) específico e singular na cidade de São Paulo, nesse início do século XXI?" (FRIN, 2017, p. 25).

Para verificar tal hipótese, acompanhei in loco o trabalho da Cia Livre, dirigida por Cibele Forjaz, e da Cia. Teatro Balagan, capitaneada por Maria Thaís. Companhias paulistanas que estrearam seus primeiros espetáculos em 2000 e mantiverem atividade continuada, não sem percalços e reformulações - o que foi uma das justificativas para que fossem escolhidas para compor o objeto da tese. Além do mais, as duas preparavam novos espetáculos no momento da pesquisa - A Livre criava Maria que virou Jonas ou a Força da imaginação (2015) e a Balagan preparava Cabras - cabeças que voam, cabeças que rolam (2016).

O ponto de partida para o espetáculo da Cia. Livre foi o ensaio no XXI: “Da força da imaginação”, do filósofo francês Michel de Montaigne (1533-1592) (MONTAIGNE, 1987). No referido ensaio, o autor narra a história de uma menina, Marie, que, ao saltar, vê seu corpo passar por uma transformação com o afloramento de um pênis. A partir daí, passa a ser chamada de Germain.

A ideia de realizar um espetáculo sobre questões de gênero partiu da atriz Lúcia Romano, que se utilizou da seguinte prerrogativa da Cia. Livre: "Qualquer um de nós pode encabeçar um projeto, desde que consiga convencer os outros a ir junto" (FORJAZ, [2007?], p. 47). Romano defendeu assim a sua proposição:

Gostei da história [de Montaigne] porque ela questiona o que aceitamos como natural, um conceito que vai mudando no decorrer das épocas. Existe, hoje, uma norma que tenta nos colocar um modelo binário [homem e mulher] que não dá conta das múltiplas possibilidades que existem. A ideia de que existe uma diferença fundamental nos corpos permite que as pessoas cometam barbaridades. (ROMANO apud BOMFIM, 2015)

A partir da escolha do tema, os integrantes da Livre convidaram alguns dramaturgos para fazer propostas ao projeto. Paralelamente, a Companhia manteve uma rotina de trabalho sobre o tema que tinha, como elemento central, o que a Cia. Livre denomina de workshop e que funciona assim: 
qual cada integrante se apropriou do tema escolhido, por meio de diferentes meios, e de que maneira está encaminhando a sua criação. Cada workshop tem o seu artista responsável, mas, invariavelmente, conta com a participação de outros integrantes, quando não de toda a equipe. Dessa maneira, ocorre o que parece ser uma contaminação prática de pontos de vista. (FRIN, 2015, p. 48-49)

Esse modus operandi permite que o processo práxico da Cia. Livre, mesmo em fases predominantemente teóricas, permaneça em produção estética, em criação de material cênico que poderá, ou não, ser utilizado no espetáculo em criação. Assim, desde os seus momentos iniciais, a criação é compartilhada em processo de recepção - nas apresentações dos workshops, ou quando convidados são recebidos em frequentes ensaios abertos invariavelmente sucedidos por conversas e debates.

Do processo de criação textual com dramaturgos convidados, resultou um texto dramático escrito por Cássio Pires que, em hibridação com uma seleção do material cênico criado no desenvolvimento dos workshops, compôs o espetáculo. Esse processo de hibridação se deu da seguinte maneira: no texto criado por Cássio Pires, a questão da transexualidade invadiu a vida de um casal (Ela e Ele) quando um pênis eclodiu na personagem Ela. Determinou-se, então, que as personagens do texto de Pires seriam interpretadas por Neo Maria e Jonas Couto, figuras transexuais criadas no processo, respectivamente, por Lúcia Romano e Edgar Castro. Também, a encenação do texto de Pires seria intercalada por intervalos nos quais Neo Maria e Jonas Couto representariam cenas criadas e lapidadas no andamento da pesquisa - tais momentos receberam o nome de camarins. Para completar, um sorteio passou a definir quem, entre Neo Maria e Jonas Couto, interpretaria as personagens Ela e Ele em cada apresentação. Assim, buscou-se, de acordo com reflexões sobre o assunto - das quais se destacam as teses de Judith Butler (2015) -, enfrentar artisticamente a imposição da relação causal e heteronormativa entre sexo, gênero, desejo e prática sexual.

Desse modo, uma estrutura metateatral em camadas foi criada. Os denominados camarins constituíram-se em momentos híbridos, nos quais expedientes épicos (relatos e canções) e de performance (improvisações, falas diretas ao público, sorteios etc.) se mesclavam e serviam de anúncio, de 
antecipação e de material referencial para o que seria apresentado na cena e nas proposições reflexivas sobre ela.

No que diz respeito à Cia. Teatro Balagan, um novo projeto é iniciado com a definição do que a Companhia define como uma imagem-espaço. A partir daí, a Companhia procura transportar-se, imergir, relacionar-se com pessoas e lugares associados com a imagem-espaço definida:

Na gênese dos processos criativos da Cia. Teatro Balagan a definição de uma imagem-espaço é um dos acontecimentos fundamentais da investigação artística. Ao fazê-la, define-se não um campo situacional, delimitado historicamente, mas uma condição territorial que carrega certos atributos míticos, uma área onde o imaginário dos artistas pode se encontrar durante os meses de ensaio. (DIAS; THAís, 2014, n.p., grifo das autoras)

Destaca-se, também, que desde a sua fundação, a Balagan interessou-se por pesquisar a representação de realidade material, simbólica, imagéti$\mathrm{ca}$, sensorial e de tantas outras que se relacionam com a humanidade, mas que não são exclusivamente premidas por ela. Então, Cabras - Cabeças que voam, cabeças que rolam mescla essas duas características fundantes da Companhia. $O$ território visitado é o da guerra, não a que dizima, mas a relacional no universo do cangaço brasileiro. Em cena, atores e atrizes representam homens, mulheres, objetos e animais, como a bala, a faca, o cachorro, a cabra - todos inseridos no contexto mitológico do conflito.

Os intérpretes da Balagan se mantêm em constante treinamento corporal e vocal. A inspiração primeira do trabalho da Companhia são as proposições do encenador russo V. E. Meierhold (1874-1940), apontado pela diretora Maria Thaís (2009, p. 1), como o seu mestre imaginário. Entretanto, a Balagan mantém pungente relacionamento com diversos profissionais que particularizam a preparação dos intérpretes de acordo com as especificidades de cada espetáculo. A presença de Maria Thaís, em proposição pedagógica, também se destaca na condução do treinamento da Companhia - lembra-se que a diretora interessa-se por pesquisar, (também) academicamente, o papel pedagógico do encenador. Destacam-se dois eixos universalizantes que se hibridizam nesse processo preparatório: o de danças e cantos tradicionais relacionados à cultura popular brasileira e o das artes marciais orientais. 
Cabras... também evidencia uma característica fundamental da Balagan. Grande parte do material produzido pela Companhia - não apenas seus espetáculos, mas também seus programas e o seu livro publicado (THAís, 2014) -, caracteriza-se por se apresentar ao espectador como estrutura a ser decifrada e completada. No caso específico de Cabras..., o espetáculo é composto por vinte curtas narrativas de autoria de Luís Alberto de Abreu. A partir da determinação do território, as narrativas foram criadas por meio de conversas entre Abreu e Maria Thaís e de trocas com os intérpretes em processo colaborativo no qual o estudo e a experimentação ocuparam lugar central. Também, um processo de extensa experimentação levou à constituição da forma final do espetáculo divida em quatro partes: Guerra; Guerra Festa; Guerra - Fé; Guerra Fogo, Paz, Fogo (THAís; PAULA, 2016, p. 5). Na peça, cada uma das quatro partes é formada por uma narrativa que serve de introdução, três que formam o corpo essencial da parte em questão, e a última, que finaliza aquele momento. A inspiração para essa estrutura veio dos trípticos, estruturas muito usadas na Idade Média, principalmente como oratórios, que emolduram quadros e permitem, a partir de uma mesma estrutura, a observação por múltiplos pontos de vista. Até que se chegasse à versão final, versões preliminares foram apresentadas e experimentadas, em diferentes localidades.

Para refletir sobre a produção de grupos e companhias, como a Livre e a Balagan, que atuam sobre auspícios colaboracionistas na atual produção teatral paulistana, evidenciou-se a necessidade da elaboração de panorama histórico contextualizante. Essa elaboração permitiu determinar, em meados dos anos 1970, em processo de enfrentamento da ditatura civil-militar então vigente no Brasil, o início do contínuo desenvolvimento da forma de produção pautada por pressupostos coletivistas na qual a utilização de expedientes épicos é preponderante. Forma, por pressupor uma estruturação (OSTROWER, 2013).

Por outro lado, o acompanhamento e o estudo das atividades das companhias trouxeram, para o centro das análises, teses defendidas por autores que referenciaram os trabalhos da Balagan e/ou da Livre, a saber: o conceito de perspectivismo ameríndio defendido por Eduardo Viveiros de Castro (2002), da miscigenação do povo brasileiro, apresentado por Darcy Ribeiro 
(2015), e o da malandragem na sociedade brasileira, tal como apresentado por Antonio Candido (1970) e Roberto DaMatta (1997).

No que diz respeito à forma épica da chamada tríade clássica - o épico, o lírico e o dramático -, em linhas gerais, ao épico é associada a narração (ROSENFELD, 2008; STALLONI, 2007). O termo grego epikos é formado por epos, que se refere à palavra e pelo sufixo ico, que carrega o significado de relativo. Épico associa-se, então, à representação de acontecimentos por meio de palavras, daí ser a principal forma de apresentação de eventos históricos, míticos, heroicos ou lendários. Por sua vez, o termo drama remete, em sua origem grega, ao conceito de ação. Em linhas gerais, o gênero dramático concerne à busca da representação da realidade por verossimilhança e por meio de personagens individualizadas que expressam sua vontade a partir de ações materializadas nos diálogos, em um tempo convencionado como o presente. No gênero dramático o mundo é representado por intermédio de relações intersubjetivas premidas pelo conflito (SZONDI, 2001).

Desse modo, o gênero dramático centra-se na individualidade, enquanto o épico associa-se ao coletivo (ABREU, 2000; BENJAMIN, 1994; SZONDI, 2001). Por isso, no contexto da produção teatral pautada por pressupostos coletivo-colaboracionistas, a utilização da cena épica tornou-se central. Nesse contexto, a perspectiva múltipla de um conjunto de artistas tende a se impor à visão de um único sujeito criador em relação a um determinado tema, o que faz com que o espetáculo seja, em tese, uma espécie de experiência resultante que hibridiza contribuições de diferentes modalidades artísticas. Obras icônicas que se apoiam na exposição imagética como espécie de materialização das experiências compartilhadas. Trabalhos que, mesmo que não explicitem claramente um viés político, resultam de um processo no qual um claro posicionamento de ordem política - a valorização do coletivo - foi fundamental.

A Livre e a Balagan apresentam as reflexões do antropólogo Eduardo Viveiros de Castro (2002) como referência conceitual para suas atividades (TEIXEIRA; ROMANO; MINA, 2012; THAÍS, 2014). Destaca-se, dentre essas referências, a tese do perspectivismo ameríndio que é "concepção, comum a muitos povos do continente [americano], segundo a qual o mundo é habitado por diferentes espécies de sujeitos ou pessoas, humanas e não humanas, que aprendem segundo pontos de vista distintos" (CASTRO, 2002, p. 347). 
Desse modo, em comunidades ameríndias estudadas pelo antropólogo, o relacional impõe-se ao absoluto e, assim, as definições de diferentes seres são transitórias e dependem de relações estabelecidas com outros seres, com a natureza e com as crenças sobrenaturais. Assim, o mundo e seus díspares habitantes se mantêm em estado de constante transformação.

Um espetáculo criado a partir de forma de produção coletivo-colaboracionista, via de regra, fricciona, em uma mesma estrutura espetacular, diversos pontos de vista a respeito de um tema e, assim, busca estabelecer uma espécie de jogo com o público no intuito de incitá-lo a concluir a obra de diferentes maneiras. Torna-se importante que um espetáculo não se apresente como absoluto, mas que apresente possibilidades de relativização a partir das elucubrações de cada integrante do público.

Em processos colaboracionistas espera-se, também, a participação de cada artista da equipe criativa em diferentes nichos da criação de um espetáculo teatral, o que permite o intercâmbio de papéis entre os integrantes do coletivo artístico. Desse modo, cada criador também permanece em constante transformação.

No que diz respeito ao conceito de miscigenação, Darcy Ribeiro (2015) defende que o denominado povo brasileiro é resultante de miscigenação de suas três matrizes: europeia, indígena e africana. Assim, comporta elementos culturais essenciais de suas matrizes, entretanto, se configura como único e singular uma vez que reelabora esses elementos e os reapresenta em contexto próprio - ao mesmo tempo semelhante e diferente do original. Desse modo, o brasileiro se formou pela absorção e, ao mesmo tempo, negação de preceitos de suas matrizes fundadoras.

Um espetáculo que se origina da forma de produção coletivo-colaboracionista, aqui em questão, tem sua unidade alcançada justamente pela miscigenação das diferentes características dos integrantes de uma equipe de criação; da interpolação de contribuições de outras linguagens artísticas; do hibridismo dos gêneros literários e de diverso material prospectado no desenvolvimento de pesquisa para a criação espetacular. A criação, então, tende a incorporar e renegar influências diversas da história do teatro brasileiro e de procedimentos de criação, de correntes e de pressupostos estéticos nacionais e internacionais. 
No que diz respeito à malandragem, em cada novo processo de criação de um espetáculo no contexto aqui apresentado, cada artista criador precisa ter segurança para apresentar suas diferentes propostas, de maneira descompromissada, sem se preocupar com erros e acertos. Assim, uma analogia pode ser feita com a tese defendida por Antonio Candido (1970). Ao analisar Memórias de um sargento de milícias (1952), obra que tem o malandro como figura central, Candido escreveu que o romance de Manuel Antônio de Almeida: "parece liberto do peso do erro e do pecado. Um universo sem culpabilidade e mesmo sem repressão” (Ibid., p. 76-77).

No contexto criativo em questão, a curiosidade deve imperar para que tudo seja experimentado em cena e retrabalhado inúmeras vezes, sem preocupações exacerbadas em relação a erros e acertos, antes que sua pertinência para o espetáculo propriamente dito seja definida. Assim, os criadores permanecem em uma espécie de jogo criativo, no qual a astúcia para apresentar novas propostas ou para se relacionar com proposições de parceiros é muito relevante.

Ainda sobre o tema da malandragem, Roberto DaMatta (1997) considera que a dialética fundamental da sociedade brasileira é a de se pretender pautar por arcabouço de leis universalizantes sob o auspício da igualdade de todos, mas se estruturar em rígida hierarquia premida principalmente pela clara diferenciação de classes socioeconômicas. A partir desse prisma, o autor analisa que tal dialética é mantida muito com o auxílio de três grandes festividades nacionais: o Carnaval, a parada militar e o culto religioso. Nesse contexto, o Carnaval - que tem no malandro um de seus principais elementos - seria o momento da inversão da estrutura hierárquica de classes vivenciada na sociedade brasileira; a parada militar, a reafirmação dessa hierarquia; e o culto religioso, a conciliação dos diferentes níveis na estrutura social.

Na forma de produção do sujeito histórico teatro de grupo paulistano, a estrutura hierárquica mais comumente presumida e, muitas vezes, idealizada, é a de hierarquia horizontal: em tese, são mantidas as especificidades de cada função no processo de criação, sem que isso represente a prerrogativa de poder de uma função sobre outra. Entretanto, o que pude auferir ao acompanhar os processos de criação mencionados aqui, principalmente na relação da função diretiva com as demais funções, é que há momentos, 
sobretudo nos iniciais, nos quais o papel da função diretiva se concentra em incentivar ao máximo a criatividade propositiva dos integrantes da equipe, que, de certa forma, comandam o processo. Entretanto, em fases de conclusão dos trabalhos, a direção tende a lançar mão da prerrogativa da função e uma espécie de afirmação hierárquica é estabelecida.

Defendi, então, que a produção continuada de agrupamentos teatrais na cidade de São Paulo acarreta um modo de fazer teatral singular, que leva a realizações estéticas e arcabouço reflexivo também singulares. Ao conjunto dos procedimentos experenciados por tais agrupamentos apliquei o termo, definido social e historicamente, de forma de produção. Essa forma de produção traz preceitos que podem ser articulados conceitualmente com determinadas teses de alguns pensadores que se debruçaram sobre as idiossincrasias do chamado povo brasileiro. Uma forma de produção, então, que é predominante épica, atua no sentido de apresentar múltiplas perspectivas de temas abordados, miscigena teorias, técnicas e procedimentos de maneira que pode ser rigorosa ou, malandramente, livre e descompromissada. Forma de produção que se associa a mecanismos públicos municipais e estaduais de financiamento à atividade cultural, como a Lei Municipal de Fomento ao Teatro (SÃO PAULO, 2002) e o Programa de Ação Cultural (ProAC) do governo estadual.

Parto, agora, para a exposição de idiossincrasias do acompanhamento das atividades da Cia. Livre e da Balagan, que permitem uma reflexão de caráter metodológico sobre o processo de pesquisa.

Para iniciar, preciso sintetizar minha experiência profissional. Formeime ator em 1995 e cantor lírico em 2008. São, então, mais de vinte anos em atividade contínua, como ator, cantor, autor e diretor de espetáculos teatrais, musicais e operísticos. Atuo também como professor de teatro desde 2002. Então, trago pela minha formação e por minha atividade profissional-artística a miscigenação que é característica marcante das produções da Livre, da Balagan e de tantas outras companhias paulistanas, e do povo brasileiro, como propõe Darcy Ribeiro (2015).

Assim, iniciei o acompanhamento das atividades das companhias valendo-me do conhecido epíteto de artista-pesquisador. No papel, basta um hífen para que os dois termos se hibridizem tranquilamente. Entretanto, vivenciei as tensões originárias pela interpolação das duas atividades, principalmente 
quando, como era o caso, a pesquisa que ali eu me dispunha a fazer não visava resultar em criação artística, em uma obra cênica (algo que estava acostumado a fazer), mas produzir um relato acadêmico pautado por parâmetros científicos. Determinei que precisava, então, transformar-me, de artista-pesquisador, em pesquisador-artista.

A principal dificuldade que enfrentei foi a de lidar com o desejo artístico de intervir no processo de criação da obra que estava sendo preparada, o que seria influenciar no próprio objeto de minha pesquisa e assim, de certo modo, desqualificá-la. A dificuldade aumentou por eu estar inserido em dois processos que incentivavam, requisitavam a participação ativa de diversos integrantes de uma equipe de criação. Assim, a sensação de estranhamento a de estar deslocado do contexto, ou até mesmo a de atrapalhar os trabalhos das companhias - acometeu-me diversas vezes. Em analogia, a dificuldade foi a de frear a propulsão de uma espécie de envolvimento dramático com o processo de criação no qual me inseria em favor de uma postura épica (distanciada) de pesquisa.

De certo modo, no desenvolvimento da pesquisa trabalhei sempre em uma espécie de fricção de perspectivas. A primeira fricção, entre as perspectivas do pesquisador e do artista, já foi enunciada. Ademais, também precisei muito me esforçar para tentar interpretar as questões que me saltavam aos olhos e que fundamentariam a minha reflexão, não exclusivamente pelo meu ponto de vista artístico, mas procurando incorporar os pontos de vista dos integrantes das equipes - obviamente em um exercício no qual a imprecisão tendia a se fazer presente. Então, tal como um espetáculo produzido pela forma de produção em questão, o meu trabalho final foi uma espécie de experiência resultante de uma interpolação de múltiplas perspectivas.

Ao assumir certo grau de imprecisão que acompanhou o trabalho, insiro a temática da malandragem nesta reflexão. Em muitos momentos, tive de frear eventuais proposições restritivas das análises e me manter aberto diante do trabalho que observava para estabelecer analogias e comparações mais livres. Enfim, em determinadas ocasiões foi preciso que eu me lançasse em voos mais descompromissados, mais malandros, para depois confrontar as impressões obtidas nesses voos com aquelas advindas de observações, leituras e análises mais rigorosas. 
O resultado dessa práxis, pode-se afirmar, foi que minha tese adquiriu como forma final uma que se aproxima do ensaio. Segundo Adorno, o ensaio é a forma crítica por excelência, pois:

O ensaio é a forma da categoria crítica do nosso espírito. Pois quem critica precisa necessariamente experimentar, precisa criar condições sob as quais um objeto pode tornar-se novamente visível, de um modo diferente do que é pensado por um autor. (ADORNO, 2003, p. 38)

Assim, ao incluir as vicissitudes do espírito crítico do autor, o ensaio

não segue as regras do jogo da ciência e da teoria organizadas [...] o ensaio não almeja uma construção fechada, dedutiva ou indutiva. Ele se revolta sobretudo contra a doutrina, arraigada desde Platão, segundo a qual o mutável e o efêmero não seriam dignos da filosofia; revolta-se contra essa injustiça cometida contra o transitório [...]. O ensaio recua, assustado, diante da violência do dogma, que atribui dignidade ontológica ao resultado da abstração. (Ibid., p. 25)

Concluo, então, com a afirmação de que a práxis de pesquisa aqui em parte e sumariamente - apresentada e que resultou em minha tese de doutorado comportou, em sua essência, elementos que auferi como essenciais do sujeito histórico teatro de grupo paulistano - objeto da pesquisa. Desse modo, acredito ter produzido um documento aberto ao questionamento e capaz de instigar o trabalho de artistas e pesquisadores das Artes Cênicas.

\section{Referências bibliográficas}

ABREU, L. A. A restauração da narrativa. O Percevejo, Rio de Janeiro, ano 8, n. 9, p. 115-125, 2000.

ADORNO, T. W. Notas de Literatura I. São Paulo: Duas Cidades; Edições 34, 2003. BENJAMIN, W. O narrador: considerações sobre a obra de Nicolai Leskov. In:

Magia e técnica, arte e política: ensaios sobre literatura e história da cultura. 7. ed. São Paulo: Brasiliense, 1994. p. 197-221.

BOMFIM, M. Companhia Livre vai ao passado para discutir questões de gênero.

O Estado de S. Paulo, São Paulo, 18 jan. 2015. Cultura. Disponível em: <https:// goo.gl/kE69s1>. Acesso em: 23 nov. 2017.

BUTLER, J. Problemas de gênero: feminismo e subversão da identidade. 9. ed. Rio de Janeiro: Civilização Brasileira, 2015. 
0 épico, o perspectivismo, a miscigenação e a malandragem nas fricções entre 0 artista-pesquisador e o pesquisador-artista

CANDIDO, A. Dialética da malandragem. Revista do Instituto de Estudos Brasileiros, São Paulo, n. 8, p. 67-89, 1970.

CASTRO, E. V. A inconstância da alma selvagem e outros ensaios de antropologia. 5. ed. São Paulo: Cosac Naify, 2002.

DAMATTA, R. Carnavais, malandros e heróis: para uma sociologia do dilema brasileiro. 6. ed. Rio de Janeiro: Rocco, 1997.

DIAS, N.; THAÍS, M. O espaço mítico. In: THAÍS, M. (org.). Balagan: Companhia de teatro. São Paulo: Cia. Teatro Balagan, 2014. Não paginado.

FORJAZ, C. Diário de bordo. In: CESARINO, P. (org.). VemVai - O caminho dos mortos. São Paulo: Cia. Livre, [2007?]. p. 46-71. (Coleção Nóz - Caderno Livre).

FRIN, L. E. Épica, em perspectiva, miscigenada e malandra: mergulhos em processos criativos da Cia. Livre e da Cia. Teatro Balagan trazem à tona forma de produção do sujeito teatro de grupo paulistano. 2017. 266 f. Tese (Doutorado em Artes Cênicas) - Instituto de Artes, Universidade Estadual Paulista, São Paulo, 2017. Disponível em: <https://goo.gl/SJ88kc>. Acesso em: 9 set. 2017.

Também sobre gêneros. In: ROMANO, L. (org.). Maria que virou Jonas ou a força da imaginação. São Paulo: Cia. Livre, 2015. p. 47-53. (Coleção Nóz Caderno Livre).

MONTAIGNE, M. E. Ensaios. 2. ed. Brasília, DF: UnB; Hucitec, 1987.

OSTROWER, F. Criatividade e processos de criação. 29. ed. Petrópolis: Vozes, 2013.

RIBEIRO, D. O povo brasileiro: a formação e o sentido do Brasil. 3. ed. São Paulo: Global, 2015.

ROSENFELD, A. O teatro épico. 6. ed. São Paulo: Perspectiva, 2008.

SÃO PAULO (Município). Lei no 13.279, de 8 de janeiro de 2002. Institui o "Programa Municipal de Fomento ao Teatro para a Cidade de São Paulo" e dá outras providências. Diário Oficial do Município de São Paulo, São Paulo, 9 jan. 2002. p. 1. Disponível em: <https://goo.gl/Aj57tY>. Acesso em: 11 dez. 2017.

STALLONI, Y. Os gêneros literários. Rio de Janeiro: Difel, 2007.

SZONDI, P. Teoria do drama moderno (1880-1950). São Paulo: Cosac Naify, 2001.

TEIXEIRA, I.; ROMANO, L.; MINA, S. (org.). Cia. Livre: experimentos e processos 2000-2011. São Paulo: Cia. Livre, 2012. (Coleção Nóz - Caderno Livre).

THAÍS, M. Na cena do Dr. Dapertutto: poética e pedagogia em V. E. Meierhold, 1911 a 1916. São Paulo: Perspectiva, 2009.

(org.). Balagan: Companhia de teatro. São Paulo: Cia. Teatro Balagan, 2014.

THAÍS, M.; PAULA, M. E sobre essa terra pasta uma cabra. In: CIA. TEATRO BALAGAN. Cabras - cabeças que voam, cabeças que rolam. São Paulo: Cia. Teatro Balagan, 2016. p. 5-7. (Programa de espetáculo).

Recebido em 16/09/2017

Aprovado em 24/11/2017

Publicado em 03/05/2018 